\title{
Stiel-Eichen und Knopperngallwespe
}

\author{
Alexandra Kehl \& Andreas König
}

\begin{abstract}
Knopper galls develop on acorns on pedunculate oak (Quercus robur) trees. They are caused by gall wesps (Andricus quercuscalicis). The small gall wesp has a life-cycle which requires Quercus robur and $Q$. cerris. The insect forms alternate sexual and parthenogenetic generations. Life-cycle and the use of knoppers are outlined.
\end{abstract}

\section{Zusammenfassung}

Knoppern entwickeln sich auf den Eicheln von Stiel-Eichen (Quercus robur). Sie werden durch Gallwespen (Andricus quercuscalicis) verursacht. Diese kleine Gallwespe hat einen komplizierten Lebenszyklus, der die Anwesenheit von zwei Eichenarten erfordert, nämlich der Stiel- und der Zerr-Eiche (Quercus robur, Q. cerris). Das Insekt bildet abwechselnd eine geschlechtliche und eine ungeschlechtliche, parthenogenetische Generation. Lebenszyklus der Gallwespe und die Verwendung von Knoppern werden vorgestellt.

\section{Unförmige Eicheln}

Manche unserer Besucherinnen und Besucher wundern sich vielleicht über die seltsamen Eichelfrüchte in unseren Gärten, die z.B. regelmäßig im Eingangsbereich des Botanischen Gartens, an mehreren Stellen im Palmengarten und auch im Tübinger Botanischen Garten auf dem Boden liegen. Weit und breit ist keine exotische Eiche zu sehen, die so einen knubbeligen, kantigen und klebrigen Fruchtbecher (Cupula) mit un regelmäßigen, z. T. flügelförmigen Längsrippen bilden könnte. Tatsächlich stammen sie von der einheimischen Stiel-Eiche (Quercus robur), und sehen doch so anders aus als sonst. Was liegt diesem Phänomen zugrunde?

\section{Der Verursacher, eine Gallwespe}

Bei den Wucherungen handelt es sich um Gallen, die von Gallwespen verursacht werden. Von den rund 1600 bekannten Arten kommen etwa 300 in Deutschland vor und etwa 100 davon findet man an Eichen. Diese unregelmäßigen Wucherungen an den Fruchtbechern werden durch die Knopperngallwespe (Andricus quercuscalicis, Cynipidae) hervorgerufen.

Ein kleines, nur wenige Millimeter großes Gallwespenweibchen hat Eier in den jungen Fruchtbecher abgelegt. In den dadurch hervorgerufenen Wucherungen (Knoppern) entwi-

Abb. 1: Knoppern, wie sie im Herbst auf dem Boden zu finden sind.

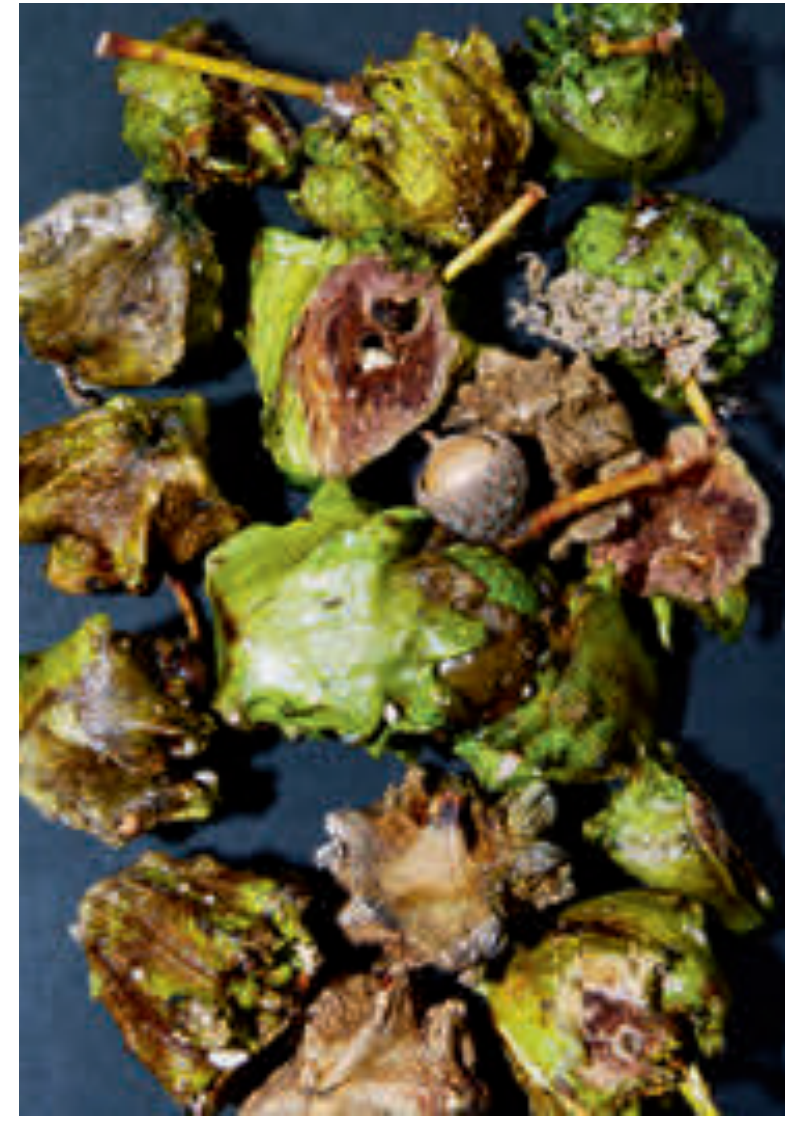

ckeln sich die Larven zu einer neuen Gallwespengeneration. Warum aber findet man diese Knoppern in unseren Wäldern so selten, dagegen häufig in Botanischen Gärten und Parkanlagen? Der Grund ist ein komplizierter Wirtsund Generationswechsel.

Im Frühjahr legen die Weibchen der ungeschlechtlichen Generation in den Knospen der männlichen Blütenkätzchen (genauer gesagt in 

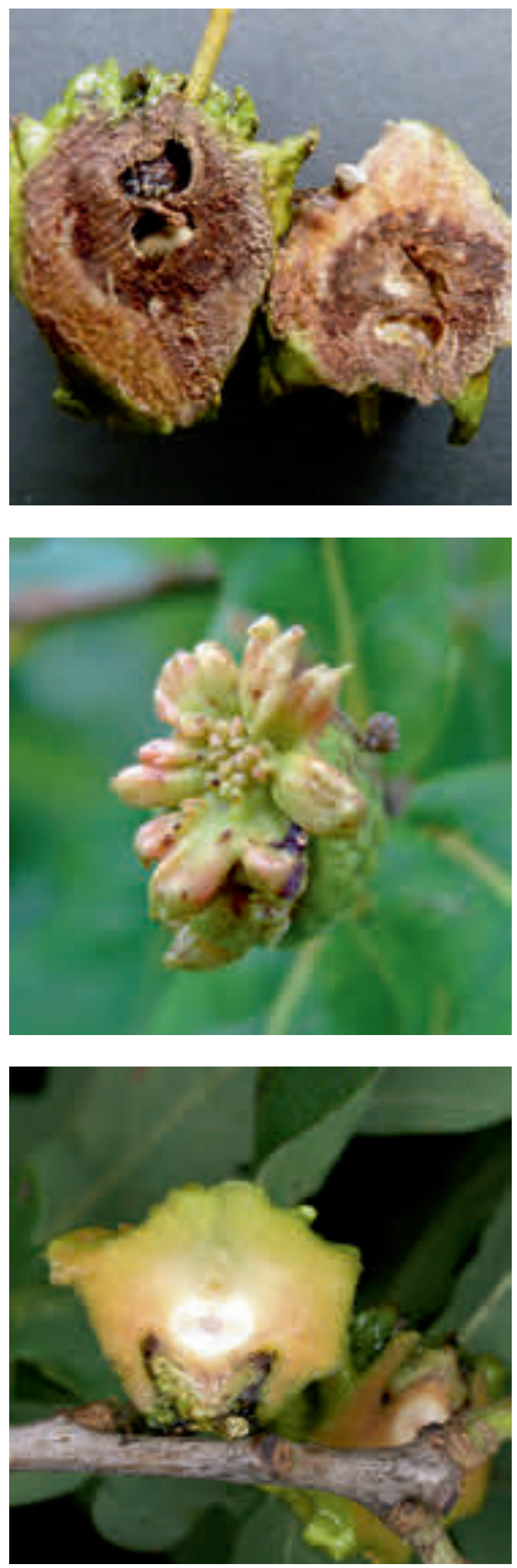

den Staubbeuteln) der südosteuropäischen Zerr-Eiche (Quercus cerris) ihre unbefruchteten Eier ab. Hier liegt also Jungfernzeugung (Parthenogenese) vor. Ein Teil der Weibchen, sogenannte Androphora, legt unbefruchtete haploide Eier, aus denen männliche Tiere hervorgehen, der andere Teil der Weibchen, die Gynophora, erzeugt durch klonale Apomixis diploide Eier, aus denen Weibchen hervorgehen (vgl. BeLLMANN 2012).

In den Blüten entstehen durch die Eiablage und Entwicklung der Larven kleine Gallen. Aus diesen schlüpfen dann im Mai die männlichen und weiblichen Exemplare der geschlechtlichen Generation der Gallwespe. Die Imagines beider Generationen unterscheiden sich nicht nur durch die unterschiedlichen Gallen, die sie hervorrufen, sondern auch morphologisch. Bis man den Zusammenhang erkannte, wurden die beiden Generationen vieler Gallwespenarten als unterschiedliche Arten beschrieben.

Nach der Paarung legen die Weibchen zwischen junger Frucht und Cupula der Stiel-Eiche ihre befruchteten Eier ab. Dadurch wird ausgelöst, dass die Eicheln verkrüppeln und sich die klebrigen, kantigen Knoppern bilden. In diesen befindet sich eine kleine dünnwandige Innengalle, die die Larve der Knopperngallwespe enthält. Durch die dicke Gallenwand und deren klebrige Oberfläche ist die Larve im Innern gut vor Feinden wie beispielsweise Schlupfwespen geschützt. Im Spätsommer oder Herbst fallen die Knoppern zu Boden. Die Larve hat sich bis zum darauffolgenden Frühjahr zur Gallwespe entwickelt. Aus den verformten, später verholzten Eichelgallen schlüpfen dann nur Weibchen, die wiederum ihre Eier in der Zerr-Eiche able-

Abb. 2 (oben): Aufgeschnittene Knoppern-Galle.

Abb. 3 (Mitte): Junge Knopperngalle im Sommer.

Abb. 4 (unten): Knopperngalle, noch nicht von der Eiche abgefallen.

Abb. 5 (Seite 87 oben): Lebenszyklus von Andricus quercussalicis.

Abb. 6 (Seite 87 unten): Zerr-Eiche, Zwischenwirt der Knopperngallwespe. 


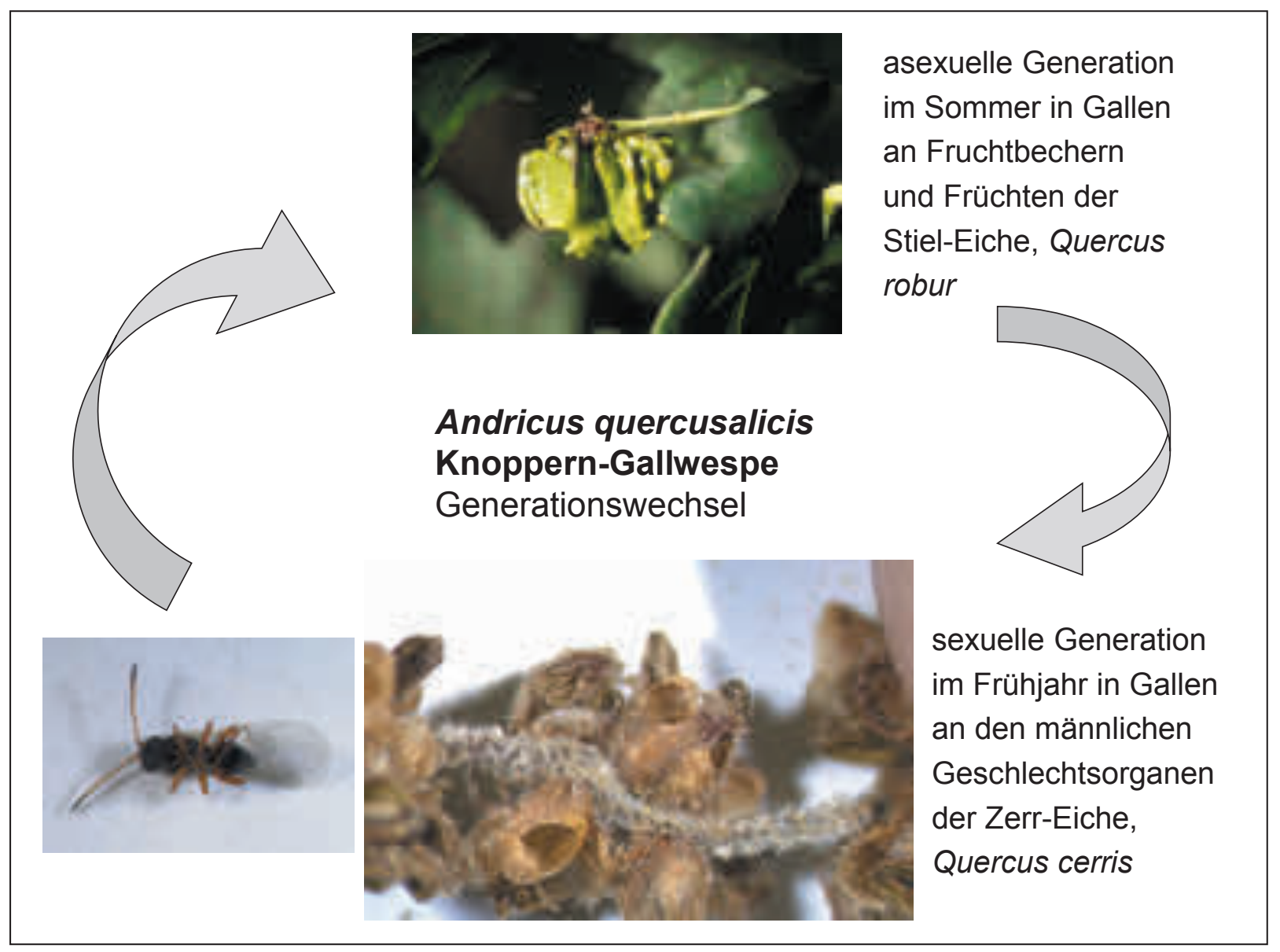

gen. Ein neuer Entwicklungskreislauf beginnt (REDFERn 2011).

Im Allgemeinen nur dort, wo beide Eichen gemeinsam vorkommen, in Südosteuropa oder in Parkanlagen, findet man auch regelmäßig Knoppern. Es gibt aber auch Hinweise darauf, dass sich zumindest stellenweise die Knopperngallwespe auch ohne Wirtswechsel beim Fehlen der Zerr-Eiche vermehren kann. Die Bildung von Knoppern schädigt bzw. schwächt den Baum kaum, allerdings sind stark deformierte Früchte nicht mehr keimfähig.

\section{Verwendung}

Auf dem Balkan und in Österreich wurden früher die Knoppern zum Färben und Gerben gesammelt, weil sie einen sehr hohen Gerbstoffgehalt (24-35\%) aufweisen. Der Handel mit Knoppern war in Österreich ein nicht zu vernachlässigender Wirtschaftsfaktor. Auch zermahlene Gallen (Knoppernmehl) wurden verwendet.

\section{Literatur}

Bellmann, H. 2012: Geheimnisvolle Pflanzengallen. Ein Bestimmungsbuch für Pflanzen- und Insektenfreunde. - Wiebelsheim.

Redfern, M. 2011: Plant galls. - New York.

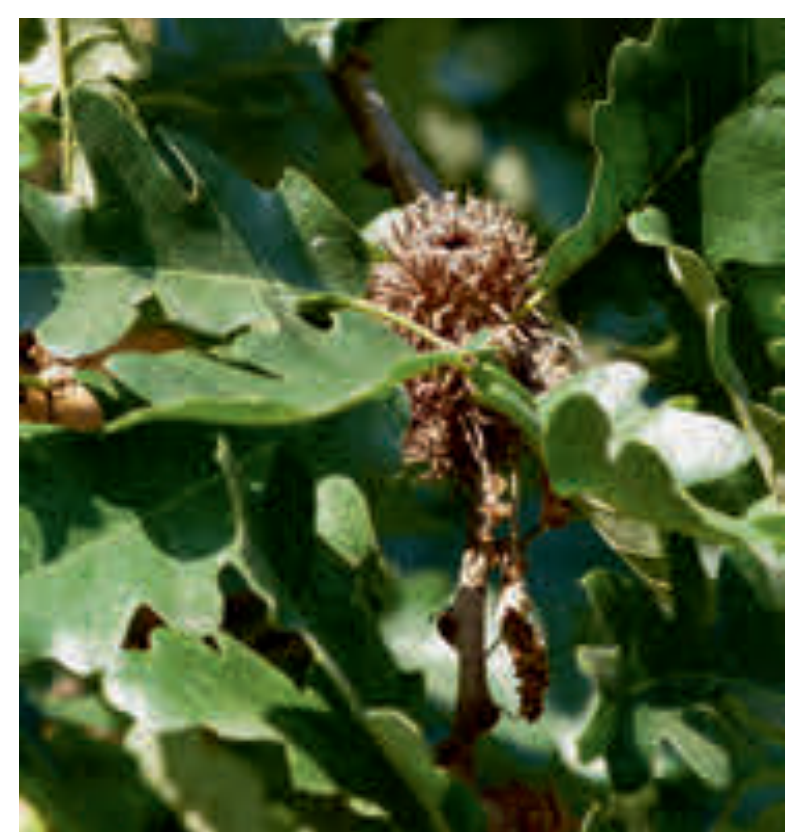

